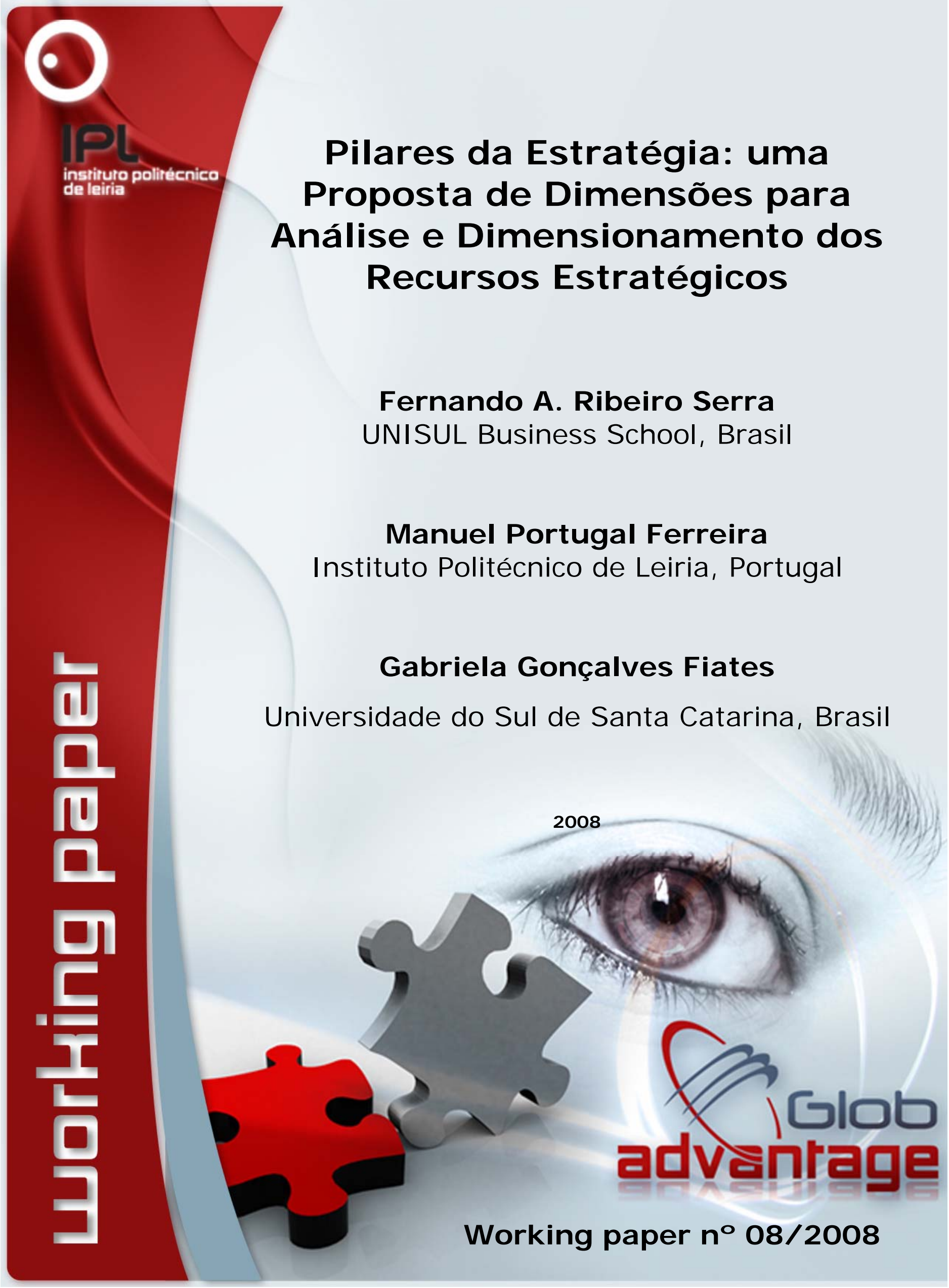




\section{globADVANTAGE}

Center of Research in International Business \& Strategy

$$
\begin{gathered}
\text { INDEA - Campus } 5 \\
\text { Rua das Olhalvas } \\
\text { Instituto Politécnico de Leiria } \\
\mathbf{2 4 1 4} \text { - } 016 \text { Leiria } \\
\text { PORTUGAL }
\end{gathered}
$$$$
\text { Tel. (+351) } 244845051
$$$$
\text { Fax. (+351) } 244845059
$$

E-mail: globadvantage@ipleiria.pt

Webpage: www.globadvantage.ipleiria.pt

WORKI NG PAPER № 08/ 2008

March 2008 


\title{
Pilares da Estratégia: uma Proposta de Dimensões para Análise e Dimensionamento dos Recursos Estratégicos
}

\author{
Fernando A. Ribeiro Serra* \\ Diretor da Unisul Business School \\ Universidade do Sul de Santa Catarina \\ Rodovia SC 401 - km 19 \\ Canasvieiras - Florianópolis \\ fernando.serra@unisul.br \\ Phone: 554832347213
}

Fax: 554832610000

\author{
Manuel Portugal Ferreira* \\ Professor da Escola Superior de Tecnologia e Gestão \\ Instituto Politécnico de Leiria \\ Morro do Lena - Alto Vieiro \\ Leiria - Portugal \\ portugal@estg.ipleiria.pt \\ Phone: 011-351-244-843317 \\ Fax: 011-351-244-820310
}

Gabriela Gonçalves Fiates

Coordenadora do Mestrado em Administração da Unisul

Universidade do Sul de Santa Catarina

Rodovia SC 401 - km 19

Canasvieiras - Florianópolis

gabriela.fiates@unisul.br

Phone: 554832610049

Fax: 554832610000

* globADVANTAGE - Center of Research in International Business \& Strategy 


\title{
Pilares da Estratégia: uma Proposta de Dimensões para Análise e Dimensionamento dos Recursos Estratégicos
}

\begin{abstract}
RESUMO
As pesquisas em estratégia têm evoluído substancialmente nos últimos 50 anos na tentativa de explicar as origens da vantagem competitiva. O caráter evolucionário e complementar dos estudos realizados resultou em diferentes escolas e abordagens. Dentre as diversas escolas teóricas nos concentraremos neste trabalho na perspectiva Resource-Based View of the Firm - "RBV" que emergiu a partir da década de 80. Embora esta vertente seja uma das perspectivas contemporâneas mais utilizadas para as pesquisas de conteúdo estratégico segundo Foss (1998), há ainda uma carência de estudos que especifiquem quais são os recursos organizacionais com caráter estratégico e de que forma estes recursos influenciam o desempenho competitivo. Nesse contexto, o objetivo desse trabalho é identificar dimensões para análise e dimensionamento dos recursos estratégicos. A pesquisa de caráter descritivo e exploratório foi desenvolvida por meio de uma extensa pesquisa bibliográfica seguida por um estudo multicasos. A partir da análise qualitativa e longitudinal dos casos selecionados, foi possível identificar que recursos comuns foram determinantes para o sucesso das empresas estudadas, destacando-se quatro dimensões a que designamos de pilares da estratégia: líder e equipe executiva, foco estratégico, aposta para o futuro e sustentação pelos recursos.
\end{abstract}




\section{NTRODUÇÃO}

$\mathrm{Na}$ evolução dos estudos de estratégia um dos grandes objetivos sempre foi a busca de uma explicação para a origem da vantagem competitiva das organizações. Esta compreensão é fundamental para entendermos porque o desempenho das empresas varia tão fortemente, não apenas com a indústria, mas também ao longo do tempo. Note, por exemplo, que uma parte significativa das empresas de grande porte do ranking da Revista Exame - Maiores e Melhores, em 1974, já foram excluídas da lista ou perderam o seu posto de liderança. Por outro lado, empresas novas - como a Gol Transportes Aéreos, que está entre as 25 empresas mais lucrativas do mundo com apenas cinco anos de existência aparecem e desafiam as empresas já estabelecidas.

Em estudos que analisam a evolução do pensamento estratégico e procuram fornecer subsídios para auxiliar a formulação de estratégias, diversos autores têm procurado identificar dimensões comuns ou distintivas às organizações que expliquem a obtenção de uma vantagem competitiva sustentável. Os últimos 50 anos têm sido profícuos no desenvolvimento da estratégia enquanto disciplina e na compreensão de como as empresas obtêm (in)sucesso. As teorias e conceitos desenvolvidos auxiliam-nos a ampliar a compreensão dos diferentes níveis de desempenho entre indústrias (PORTER, 1980, 1985) e entre empresas (BARNEY, 1991).

Neste trabalho nos concentraremos na perspectiva Resource-Based View of the Firm - "RBV" que emergiu a partir da década de 80 para se tornar uma das perspectivas contemporâneas mais utilizadas para as pesquisas de conteúdo estratégico, principalmente por seu rigor analítico e relevância na prática administrativa (FOSS, 1998). A proposição central 
dessa vertente é que a fonte da vantagem competitiva se concentra primordialmente nos recursos e nas competências desenvolvidos e controlados pelas empresas e apenas secundariamente na estrutura das indústrias nas quais elas se posicionam (VASCONCELOS e CIRYNO, 2000).

No entanto, nem todos os recursos organizacionais são considerados estratégicos e há ainda uma carência de estudos que especifiquem quais são os recursos organizacionais com caráter estratégico e de que forma estes recursos influenciam o desempenho competitivo.

Nesse contexto, o objetivo desse trabalho é identificar dimensões para análise e dimensionamento dos recursos estratégicos, buscando dessa forma, apresentar uma proposição teórica, que contribua para o desenvolvimento dos conhecimentos acerca da vantagem competitiva.

A pesquisa de caráter descritivo e exploratório foi desenvolvida por meio de uma extensa pesquisa bibliográfica seguida por um estudo multicasos, envolvendo cinco empresas. Para identificar que recursos comuns foram determinantes para o sucesso das empresas estudadas foi realizada uma análise qualitativa e longitudinal.

O trabalho está dividido em quatro partes principais. Na primeira parte é feita uma revisão teórica dos aspectos fundamentais da RBV. Na seqüência, são apresentados os procedimentos metodológicos justificando a seleção dos casos de análise, a apresentação dos casos com a respectiva análise e proposições resultantes do estudo, seguida das conclusões do trabalho.

\section{REFERENCI AL TEÓRI CO}

O trabalho de Penrose (1959) é reconhecido como a base da abordagem teórica da Resouce-Based View (RBV) (WERNERFELT, 1984; 
RAMOS-RODRIGUEZ e RUIZ-NAVARRO, 2004). Penrose (1959) argumenta que o crescimento das firmas depende do uso efetivo de recursos heterogêneos. Assim, na abordagem da RBV, as firmas são consideradas como feixes de recursos heterogêneos (WERNERFELT, 1984; PETERAF, 1993), um feixe único de recursos e de relacionamentos (RUMELT, 1984).

Dentro dessa perspectiva, a vantagem competitiva é então, explicada pelo desenvolvimento e utilização de recursos. Assim, a forma como a organização utiliza seus recursos é determinante para se atingir uma vantagem competitiva e, portanto, um desempenho superior (WERNERFELT, 1984; BARNEY, 1991; GRANT, 1988).

Cabe salientar, porém, que nem todos os recursos são fontes de vantagem competitiva sustentável. Apenas recursos com determinadas características são capazes de conferir e sustentar um desempenho superior (DIERICKX; COOL, 1989; BARNEY, 1991; PETERAF, 1993; AMIT e SCHOEMAKER, 1993).

Barney (1991) apresenta um framework para a identificação das características de recursos estratégicos. Sua utilização visa possibilitar definir os recursos que possam constituir fontes de vantagem competitiva. Os recursos são determinantes para a obtenção de vantagem competitiva, porém, nem todos os recursos podem gerar altos níveis de ganhos econômicos ou, talvez não sejam sustentáveis e defensáveis contra a competição, ou seja, nem todos são estratégicos. Para que os recursos sejam relevantes devem ser simultaneamente: valiosos, raros, imperfeitamente imitáveis e não substituíveis (BARNEY, 1991), conforme Quadro 1. 
QUADRO 1. Recursos Organizacionais

\begin{tabular}{|l|l|}
\hline \multicolumn{1}{|c|}{ Recursos } & \multicolumn{1}{c|}{ Descrição } \\
\hline Valiosos & $\begin{array}{l}\text { Recursos que permitem a uma organização conceber } \\
\text { estratégias que melhorem sua eficiência e eficácia, } \\
\text { aproveitando oportunidades ou minimizando as ameaças. }\end{array}$ \\
\hline Raros & $\begin{array}{l}\text { Recursos valiosos não podem ser fonte de vantagem } \\
\text { competitiva sustentável se são acessíveis a vários } \\
\text { competidores, uma vez que cada um de seus detentores terá } \\
\text { a capacidade de explorá-los, implementando estratégias } \\
\text { comuns, o que levaria a obterem apenas retornos médios. }\end{array}$ \\
\hline $\begin{array}{l}\text { Imperfeitamente } \\
\text { imitáveis }\end{array}$ & $\begin{array}{l}\text { Mesmo que sejam valiosos e raros, os recursos só são fonte } \\
\text { de vantagem competitiva sustentável se as organizações que } \\
\text { ainda não os possuem não puderem obtê-los com demasiada } \\
\text { facilidade. }\end{array}$ \\
\hline $\begin{array}{l}\text { Não } \\
\text { substituíveis }\end{array}$ & $\begin{array}{l}\text { Os recursos devem ser não-substituíveis, ou seja, não devem } \\
\text { possuir um equivalente que não seja raro e imperfeitamente } \\
\text { imitável. Pois a imitação, ou a substituição por outro recurso } \\
\text { estratégico é uma ameaça à sustentabilidade da vantagem } \\
\text { estratégica, tornando o recurso original obsoleto, perdendo } \\
\text { sua capacidade de gerar valor. }\end{array}$ \\
\hline
\end{tabular}

Fonte: Baseado em BARNEY, 1991; DIERICKX; COOL, 1989.

Quanto à classificação, Barney (1991) salienta que existem várias nomenclaturas para se categorizar os recursos quanto a seus atributos e quanto ao potencial de gerar vantagem competitiva. Wernerfelt (1984) ressalta que os recursos à disposição da firma englobam tanto os recursos tangíveis, quanto os intangíveis. Barney (1991, p. 101) sugeriu então que os recursos podem ser classificados em: recursos de capital físico como tecnologia física (equipamentos), acesso a insumos etc.; recursos de capital humano - como treinamento, experiência, inteligência, relacionamentos e capacidade gerencial individual; e recursos de capital organizacional - como a estrutura formal da organização, o planejamento formal e informal e sistemas de coordenação e controle, bem como relacionamentos informais etc.

Os bens tangíveis (de capital físico) são comercializados geralmente nos mercados de fatores, reduzindo assim a dimensão de "raridade". No entanto, muitos recursos intangíveis (de capital humano e/ou 
organizacional) não podem ser adquiridos num mercado nem são dissociáveis da firma, tendo antes de ser desenvolvidos e acumulados internamente, dependendo de tempo e outros recursos. Deste modo, os recursos intangíveis tendem a tornarem-se específicos e, portanto, raros e de difícil imitação (DIERICKX e COOL, 1989).

Michalisin, Smith e Kline (1997) desenvolveram um modelo conceitual no qual ressaltam a importância dos recursos intangíveis para as organizações e a obtenção de vantagem competitiva. Os autores afirmam que: (a) os recursos estratégicos são intangíveis por natureza; (b) nem todos os recursos intangíveis são estratégicos; e (c) a reputação organizacional, reputação do produto, know-how dos empregados e cultura organizacional possuem características de recursos estratégicos.

Porém, apenas o fato do recurso ser intangível não o classifica como estratégico. Alguns recursos tangíveis também podem ser estratégicos. A questão reside em saber o que qualifica um recurso como estratégico, ou não. O modelo de Peteraf (1993) apresenta quatro fatores essenciais que os recursos devem possuir para serem fonte de vantagem competitiva.

O modelo tem duas suposições essenciais - heterogeneidade e mobilidade imperfeita, e duas condições relativas aos recursos que levam as organizações à vantagem competitiva sustentável - os limites ex-ante e expost à competição (MICHALISIN, SMITH e KLINE, 1997), conforme segue:

a) Heterogeneidade. A heterogeneidade dos recursos e capacidades entre as organizações, assegura uma posição de superioridade ou inferioridade de recursos e, portanto, dos ganhos. Barney (1991) afirma que a distribuição de recursos entre as organizações é naturalmente heterogênea devido aos diferentes níveis de eficiência de alguns deles, a. 
escassez de fatores produtivos superiores ou de restrições de disponibilidade.

b) Mobilidade imperfeita. A imobilidade ou mobilidade imperfeita dos recursos permite sustentar a vantagem competitiva dentro da firma. Os recursos têm mobilidade imperfeita se não forem comercializáveis ou, mesmo que sejam comercializados, tenham mais valor na empresa que os utiliza atualmente que teriam em outra empresa (PETERAF, 1993).

c) Limites ex-post. Para que um recurso seja fonte de vantagem competitiva sustentável, é necessário que a heterogeneidade seja preservada. Isto é, mesmo posteriormente à obtenção da vantagem competitiva, devem existir limites à competição por tais recursos, protegendo-os, criando "mecanismos de isolamento", forças que protejam a empresa da imitação e Ihe permita preservar os seus ganhos (RUMELT, 1984; PETERAF, 1993).

d) Limites Ex-Ante. Para que a organização adquira uma posição superior de recursos deve haver uma competição limitada por aqueles recursos, decorrente de imperfeições dos mercados de fatores como, por exemplo, assimetria de informação ou percepção (BARNEY, 1991). Sem imperfeições, as organizações só teriam ganhos médios (PETERAF, 1993). O argumento base é que o desempenho econômico depende não só dos ganhos gerados por sua estratégia, mas também do custo dessa estratégia (BARNEY, 1986; PETERAF, 1993).

Cabe ressaltar ainda, que a forma como a organização emprega seus recursos é que define a singularidade de cada empresa e o seu desempenho competitivo diferenciado. Penrose (1959) já alertava sobre isso ao dissertar que diferentes utilizações ou combinações dos mesmos recursos geram 
resultados também diferentes. Para Dosi e Teece (1993), a utilização de recursos de forma diferenciada visa desenvolver competências em diferentes focos de ação da empresa, seja no âmbito das decisões de produção e de formação de preços (competência alocativa); na habilidade de desenvolver e projetar novos produtos e processos (competência técnica); na determinação das políticas e estrutura organizacional (competência administrativa); no desenvolvimento de relações de compra e venda (competência transacional) ou na mudança das competências existentes pela inovação e aprendizagem.

Apesar da relevância para as organizações do desenvolvimento dos estudos da RBV acerca do desempenho competitivo, há ainda uma carência de estudos que especifiquem quais são os recursos organizacionais com caráter estratégico e de que forma estes recursos influenciam o desempenho competitivo. Estas lacunas podem, parcialmente, explicar as críticas atuais à RBV, pelas definições imprecisas dos termos fundamentais; pelo seu teor tautológico, redundante - por não identificar a priori se um determinado recurso é fundamental e qual a quantidade de recursos necessários; por se abster de determinar o valor dos recursos, focando a análise em recursos individuais; e finalmente, pelo fato da RBV ser ou não uma novidade em função de seus antecedentes teóricos (GALBREATH, 2004; PRIEM e BUTLER, 2001).

Barney (2001) vem em defesa da RBV argumentando que apesar de não existirem testes para identificar os recursos estratégicos, estes precisam ser avaliados nos contextos das firmas. Adicionalmente, se é verdade que a RBV não pode gerar uma lista de potenciais recursos, pode especificar características que estes devem possuir para serem fonte de 
vantagem competitiva. Para tal, é importante compreender a necessidade de adotar uma análise dinâmica e do estudo das interações competitivas entre firmas ao longo do tempo. Inserido neste contexto de discussões e questionamentos, esse estudo buscou identificar dimensões para análise e dimensionamento dos recursos.

\section{PROCEDI MENTOS METODOLÓGICOS}

De acordo com Vergara (1997), o tipo de pesquisa pode ser definido quanto aos fins e quanto aos meios de investigação. Quanto aos fins, esta pesquisa é explicativa, pois objetiva esclarecer um novo conjunto de dimensões que contribua para a explicação da vantagem competitiva. Também é descritiva, pois expõe as características de casos de organizações. Quanto aos meios a pesquisa é bibliográfica, na medida em que recorreu a casos de estudo de empresas que serviram para subsidiar artigos e livros clássicos que representam a evolução dos estudos de estratégia.

O método de estudo de casos é relevante para estudos longitudinais que tentam explicar "Por que" ou "Como" certas empresas obtêm sucesso, ou falham, ao longo do tempo (YIN, 2005). Michael Porter, o autor mais citado nos estudos de estratégia, segundo estudo bibliométrico de RamosRodriguez e Ruiz-Navarro (2004), ressalta a importância dos estudos de caso em sua pesquisa a cerca da estratégia: "De posse dos ricos conhecimentos do setor e de empresas, provenientes de muitos estudos de caso, pude oferecer uma visão mais sofisticada da competição nos setores e proporcionar alguma estrutura à questão de como uma empresa poderia ter um desempenho melhor que suas rivais." (PORTER, prefácio da $16^{\circ}$ edição, p. XVII, 1986). Posteriormente, ao se referir à necessidade de testes 
empíricos para a confirmação de modelos e frameworks teóricos, o autor observou que: "O maior uso de estudos de caso, tanto em livros, como em artigos, será necessário para o progresso real neste estágio" (PORTER, 1991, p. 99).

A seleção dos casos de empresas a serem estudadas se baseou na literatura considerada relevante nos estudos brasileiros de estratégia. Bignetti e Paiva (2001) estudaram as citações de autores de estratégia na produção acadêmica brasileira entre 1997 e 2001. Neste período Michael Porter, Henry Mintzberg, Gary Hamel e C. K Prahalad foram os autores mais citados. Bignetti e Paiva (2001) constataram também, que algumas obras tiveram especial realce neste período: "Estratégia Competitiva" e “Vantagem Competitiva” de Michael Porter (1986 e 1989), "Competindo pelo Futuro" de Hamel e Prahalad (1995), "Feitas para Durar" de Collins e Porras (1998), "A Estratégia e o Cenário dos Negócios" de Ghemawat (2000) e “Safári da Estratégia" por Mintzberg, Ahlstrand e Lampel (2000). Acrescemos a estas o livro "Estratégia do Oceano Azul" por Kim e Maugborne (2005). Por fim, incluímos o artigo de Pascale (1984) “o efeito Honda", pelo entusiasmado debate que relançou entre os especialistas sobre os méritos relativos da estratégia prescritiva versus a estratégia emergente. Em todas estas obras existe referência explícita a um conjunto de empresas que simbolizam casos de sucesso. Pela relevância dessas empresas dentro da evolução dos estudos de estratégia essas empresas compõem a nossa amostra e serão alvo de análise. O Quadro 2 apresenta as empresas selecionadas para o estudo e os livros e artigos que as referem, mostrando a relevância das mesmas para nossa análise. 
QUADRO 2. Empresas selecionadas a partir das referências selecionadas

\begin{tabular}{|c|c|c|}
\hline Empresa & $\begin{array}{c}\text { Referência de } \\
\text { escolha }\end{array}$ & Referências adicionais \\
\hline HONDA & Pascale, R. (1984) & $\begin{array}{l}\text { Pascale, R. (1996); Porter, M. (1989) } \\
\text { Pascale, R., Mintzberg, H., Goold, M. \& } \\
\text { Rumelt, R. (1996) } \\
\text { Mintzberg, H. \& Quinn, J. (2001) ; Derisbourg, } \\
\text { Y. (1993) } \\
\text { Kaplan, R. \& Norton, D. (1997) ; } \\
\text { Mintzberg, H., Ahlstrand, B. \& Lampel, J. } \\
\text { (2000) } \\
\text { Pascale, R., Christensen, E. T. (1989) } \\
\text { Hamel, G. \& Prahalad, C. K. (1989) e (1990) }\end{array}$ \\
\hline SWATCH & $\begin{array}{l}\text { Hamel, G. \& } \\
\text { Prahalad, C. K. } \\
\text { (1995) }\end{array}$ & $\begin{array}{l}\text { Hamel, G. \& Prahalad, C. K. (1995a) } \\
\text {;Zehnder, D. (1994) } \\
\text { Moon, Y. (2004); Reavis, C. (2000) } \\
\text { Kim, W. \& Maugbogne, R. (1999); (2000)e } \\
(2005)\end{array}$ \\
\hline $\begin{array}{l}\text { GENERAL } \\
\text { ELECTRIC } \\
\text { (GE) }\end{array}$ & $\begin{array}{l}\text { Ghemawat, P. } \\
\text { (2000) } \\
\text { Kay, J., Mckiernan, } \\
\text { P. \& Faulkner, D. } \\
\text { (2003) }\end{array}$ & $\begin{array}{l}\text { Mintzberg, H., Ahlstrand, B. \& Lampel, J. } \\
(2000) \\
\text { Tichy, N. \& Charan, R. (1989) } \\
\text { Kleiner, A. (2003); Welch, J. \& Welch, S. } \\
\text { (2005) } \\
\text { Welch, J. \& Byrne, J. (2001) } \\
\text { Ulrich, D., Kerr, S. \& Ashkenas, R. (2002) }\end{array}$ \\
\hline $\begin{array}{l}\text { SOUTHWEST } \\
\text { AIRLINES } \\
\text { (SWA) }\end{array}$ & Porter (1996) & $\begin{array}{l}\text { Porter (1989); Ghemawat, P. (2000); Heskett, } \\
\text { L. (1994) } \\
\text { Kim, W. C. \& Maugborgne, R. (2005); } \\
\text { Carrigan, L. (1994) } \\
\text { Hamel, G. \& Prahalad, C. K. (1995); Frei, F. \& } \\
\text { Hajim,C. (2004) } \\
\text { Kelleher, H. (1997) }\end{array}$ \\
\hline MICROSOFT & $\begin{array}{l}\text { Ghemawat, P. } \\
(2000)\end{array}$ & $\begin{array}{l}\text { Kim, W. \& Maugborgne, R. (2005) ; Staufer, } \\
\text { D. (1997) } \\
\text { Bartlett, C. \& Wozny, M. (2001); Lowe, J. } \\
\text { (1998) } \\
\text { Rosenzweig, P. (1991); Stross, R. (1996) }\end{array}$ \\
\hline
\end{tabular}

Fonte: Os Autores.

A pesquisa foi então desenvolvida pela análise qualitativa e longitudinal de cada um dos casos selecionados, visando identificar que recursos em comum foram determinantes para o sucesso das empresas estudadas.

\section{APRESENTAÇÃO DOS CASOS}

\section{A HONDA}

O caso da Honda surge no artigo "Perspectives on strategy: The real story behind Honda's success" de Richard Pascale, publicado em 1984 na 
California Management Review. A importância deste artigo é legitimada por Mintzberg et al. (1996, p. 78) que afirmaram a seu respeito: “[t]alvez, nenhum outro artigo publicado na literatura de gestão tenha tido tanto impacto como a peça de Richard Pascale na California Management Review, o "Efeito Honda"." Este artigo gerou uma discussão entre pesquisadores e consultores no CMR Forum (MINTZBERG, PASCALE, GOOLD e RUMELT, 1996) e dividiu a discussão sobre estratégia prescritiva e emergente a partir do relatório do Boston Consulting Group (BCG) de 1975 sobre a perda de competitividade da indústria inglesa de motocicletas e do sucesso da Honda nos EUA e, da comparação com o estudo de caso realizado por Pascale (1984).

Dos artigos de Pascale $(1984,1996)$ emergem alguns dados úteis, recolhidos em entrevistas com executivos que participaram da expansão da Honda para os EUA. Soichiro Honda era um gênio, inovador, com grande ego e temperamental - características usuais nos empreendedores. Takeo Fujisawa, que passou a sócio em 1949, ao prover dinheiro e forças de gestão de marketing e finanças, estabeleceu as bases para o desenvolvimento da empresa. Existia um foco claro, uma aspiração, segundo Fujisawa seu "sonho grandioso". Segundo Fujisawa a visão de Soichiro Honda era focada na tecnologia: "não havia fim para sua perseguição à tecnologia". A Honda desenvolveu um motor de quatro tempos com o dobro da potência, o que aumentou a demanda fortemente, forçando a organizar a empresa e a investir na produção em massa.

O fato é que a estratégia da Honda foi bem sucedida onde a priori deveria ter falhado. Segundo Mintzberg et al. (2000) a entrada no mercado americano de motocicletas, em 1959, seria inadequada dado que a Honda 
entrou com motos pequenas num mercado onde as motos de grande porte eram, tipicamente, preferidas. Também a entrada no mercado de automóveis, em 1977, tinha grande probabilidade de insucesso dado que existiam concorrentes eficientes no Japão, nos EUA e na Europa e a Honda tinha pouca experiência com automóveis e não dispunha de um sistema de distribuição estruturado para este tipo de produto.

Da avaliação dos casos de estudo da Honda sobressai um primeiro fator essencial para o sucesso da Honda: o empreendedor, Soichiro Honda e a sua equipa executiva (Top Management Team - TMT). Destaca-se ainda a forma como o Sr. Honda definiu o foco da companhia na sua busca por tecnologia de motorização. Um outro aspecto que fica evidente nos textos é que na busca pelo foco; a empresa assume determinados riscos, ou seja, faz suas apostas para obter maiores recompensas. Estas apostas são ilustradas, por exemplo, na sua entrada no mercado americano, com tantas restrições e a despeito da concorrência forte, tanto para as motocicletas, como para os automóveis. Para dar suporte a esta aposta, dentre os diversos recursos utilizados e desenvolvidos, evidencia-se a preocupação com a qualificação dos recursos humanos e a atenção aos aspectos financeiros para sustentar o crescimento da empresa.

\section{A SWATCH}

A Swatch e seu executivo principal na década de 80 e 90, Nicolas Hayek, foram objetos de diversos casos e entrevistas com destaque para o livro de Hamel e Prahalad, de 1995, Competindo pelo Futuro, que influenciou e ainda influencia a produção acadêmica nacional. O sucesso da Swatch está relacionado com a perda de mercado da indústria de relojoaria suíça e sua reascensão. Logo após a Segunda Guerra Mundial existiam 
cerca de 2500 empresas suíças de relojoaria que representavam $80 \%$ da produção mundial e 99\% das importações norte americanas (MOON, 2004). A concorrência mundial fez-se sentir a partir da década de 60 com a introdução de uma linha de relógios descartáveis da norte americana Timex, e com ganhos de visibilidade das marcas japonesas Hattori-Seiko e Citizen. Apesar do crescimento da demanda mundial de relógios, a fatia de mercado das empresas suíças decresceu (MOON, 2004).

O conceito de relojoaria promovido por Hayek para a Swatch foi controverso por diversos motivos (MOON, 2004): pelo nível de integração vertical - construção e montagem de um relógio de quartzo suíço de baixocusto totalmente em território suíço; alteração no produto e alteração na promoção. A Swatch apostou em design e coleções (KIM e MAUGBORGNE, 1999; MOON, 2004). Investiram fortemente em propaganda e em material de ponto de venda, promoções e endosso (MOON, 2004). Com diversas inovações que introduziu na concepção e produção o peso dos custos da mão-de-obra sobre o preço caiu de $10 \%$ para $1 \%$ e a quantidade de peças de 91 para 51. Para viabilizar este conceito de relojoaria suiça a preço acessível e como instrumento de moda foi necessário convencer os banqueiros, céticos, que a indústria suíça pudesse fazê-lo (HAMEL e PRAHALAD, 1995). Com estas alterações, os custos totais de fabricação da Swatch ficaram quase $30 \%$ inferiores aos dos concorrentes de Honk Kong (KIM e MAUGBORGNE, 2000).

Ao longo do tempo e do desenvolvimento da SWATCH, Hayek sempre se aproximou das pessoas como um chefe carismático e competente, sua liderança e o comprometimento de sua equipe destacam-se como um dos fatores de sucesso da empresa (MOON, 2004). 
No caso da Swatch, a liderança e o papel de Nicholas Hayek e o desenvolvimento e atuação do TMT da Swatch foram fundamentais para o foco de reconstrução do setor relojoeiro suíço. Destacam-se, também, as diversas apostas que orientaram a alocação e desenvolvimento de recursos, como sejam: como a mudança do apelo do relógio, o estilo e o savoir faire europeu e ter uma marca global líder no mercado de baixo preço liderado pelos japoneses com o uso de tecnologia que não dominavam. Na base de todos os recursos e atividades, a sustentabilidade financeira foi conseguida pelo investimento dos bancos e pelo controle rigoroso de custos e despesas e, principalmente, pelos recursos humanos que foram desenvolvidos para uma nova forma de trabalhar e sustentar as inovações necessárias.

\section{A GENERAL ELECTRI C (GE)}

A General Electric (GE) é uma empresa multinacional presente nos seis continentes. Fundada em 1892 por Thomas Edison atingia um volume de receitas de cerca de 150 bilhões de dólares em 2005. O seu CEO mais reconhecido foi Jack Welch, pelas transformações que este introduziu e que permitiram eliminar "gorduras", com aumento da produtividade e de crescimento da base da pirâmide (KLEINER, 2003). A GE tem sido caso de estudo e referência em muitos trabalhos acadêmicos, tais como: Ghemawat (2000); Kay, Mckiernan e Faulkner (2003); Mintzberg, Ahlstrand e Lampel (2000), além dos próprios trabalhos de Welch.

Kay, Mckiernan e Faulkner (2003) apontam a GE como a única empresa que por si só pode representar a evolução da estratégia em negócios. A GE tanto liderou como acompanhou todos os grandes desenvolvimentos em administração estratégica das últimas quatro décadas. 
Para Jack Welch, que foi CEO entre 1981 e 2001, a visão é o elemento central da estratégia bem sucedida da GE (TICHY e CHARAM, 1989, p. 113): "bons líderes de negócios criam uma visão, articulam a visão, apaixonadamente possuem a visão, e sem misericórdia a dirigem para se completar." São dois os elementos chave da visão de Welch segundo o relatório anual de 1988 (TICHY e CHARAM, 1989, p.113): “Vamos tocar somente negócios que sejam o número um ou o número dois nos seus mercados globais". Apesar deste objetivo ambicioso a estratégia assenta em manter um nível elevado de flexibilidade e autonomia das diversas unidades estratégicas de negócio para aproveitar as oportunidades e fazer crescer o todo corporativo.

Para atingir os objetivos Welch usou novas ferramentas como o workout e o 6 sigma (ULRICH et al., 2003). No entanto, as dimensões determinantes do sucesso da GE iniciam com a liderança de Jack Welch e o papel do TMT que foram fundamentais para os desafios de melhorar a competitividade da GE. Welch deixou claro também que o foco do negócio e, assim, a primeira aposta determinante para o sucesso da empresa foi livrar-se ou reestruturar os negócios que estariam em desacordo com este foco. A atenção aos recursos humanos é, também, reconhecida como um fator determinante para o alto desempenho da organização. A sustentabilidade financeira foi conseguida através da eliminação de gorduras e das receitas adicionais.

\section{A SOUTHWEST AI RLI NES (SWA)}

Rollin King e Herbert Keleher fundaram a Air Southwest em 1967, no Texas, Estados Unidos. Atualmente, a Southwest Airlines é líder em seu segmento e uma das 5 maiores empresas de aviação do mundo 
considerando a lucratividade. A seleção da Southwest Airlines para este estudo emerge do artigo de Michael Porter publicado em 1996 na Harvard Business Review, “What's strategy?". Segundo Porter (1996, p.64), a Southwest "demarcou uma estratégia única e valiosa, com base num conjunto de atividades sob medida".

A Southwest Airlines Company (SWA) oferece, essencialmente, vôos de curta distância, a baixo preço e ponto a ponto entre cidades de porte médio e aeroportos secundários de cidades grandes norte americanas. A Southwest não se focaliza apenas nos clientes corporativos, mas antes em todos os públicos, desde que sensíveis ao preço. Assim, a SWA foca quatro atributos: serviços amigáveis, velocidade, frequência de vôos e preço. Não investe em refeições, sala de espera e escolha de assentos, ao contrário das tradicionais companhias de aviação civil. O slogan, ou mensagem, da SWA evidencia a sua estratégia de negócio: “Velocidade do avião a preço de carro" (Porter, 1996).

Kim e Maugborgne (2005) também examinam a Southwest Airlines, referindo, por exemplo, que para construir uma estratégia de sucesso as empresas precisam reconstruir as fronteiras do mercado para se libertar da concorrência. Uma das fronteiras são os setores alternativos. Neste caso, a Southwest concentrou-se no automóvel como alternativa ao avião, oferecendo a viagem aérea em trechos curtos a preços compatíveis ao do custo do transporte por automóvel. Hamel e Prahalad (1995) comentam o problema da competição não tradicional: retardatários versus desafiantes, líderes versus inovadores, inerciais e copiadores versus criativos. Neste caso, a United Airlines e a American Airlines só acordaram para rever a sua 
forma de competição quando a SWA emergiu como a companhia aérea mais lucrativa dos EUA.

Também Ghemawat (2000, p. 116) usou o caso da SWA para exemplificar a diferença entre atividades e recursos. Onde "recursos podem ser vistos como variáveis de estoque e atividades como variáveis de fluxo". Pela RBV, o autor explica a vantagem da SWA na capacidade de simplificar as atividades, no maior emprego das pessoas, no padrão de distribuição dos recursos que possibilita que os tempos em terra sejam menores.

Destacando os fatores determinantes para o sucesso da empresa apontamos primeiramente o líder da SWA, Kelleher, que teve um papel fundamental no elevado desempenho da empresa. Kelleher focou a companhia em buscar proporcionar uma viagem de avião ao custo de uma viagem de automóvel. Destacam-se, ainda, que suas apostas eram inerentes à própria inovação em proporcionar o serviço aéreo de forma distinta das companhias aéreas rivais. Para sustentar a aposta foi fundamental o desenvolvimento dos recursos humanos necessários para dar sustentação às atividades, bem como à implementação de atividades que garantissem a sustentação financeira proporcionando custos baixos. As relações com os colaboradores são essenciais para garantir a menor rotatividade de pessoal.

\section{A MI CROSOFT}

A Microsoft é uma das maiores empresas do mundo e um dos seus fundadores, Bill Gates, o homem mais rico do mundo, segundo dados da revista Forbes em 2005. O crescimento da Microsoft foi baseado na visão inicial de Gates para a organização: “um computador em cada mesa e em cada lar, todos rodando software Microsoft em cada computador" 
(STANFER, 1997, p. 3). Ghemawatt (2000) usou o exemplo da Microsoft para seu capítulo sobre recursos e capacidades. Apresentando o desenvolvimento de capacidades flexíveis.

Quinn e Hilmer (1994) utilizaram o caso da Microsoft para ilustrar o conceito de "Strategic outsourcing": concentrar os recursos próprios num conjunto de "essências competitivas" e terceirizar atividades que seriam tradicionalmente intrínsecas a qualquer companhia. O termo "estratégias de essência competitiva" foi usado posteriormente por Hamel e Prahalad (1995) para explicar o seu conceito de competência central das organizações. A idéia não é concentrar-se em uma coisa de cada vez, mas sim focalizar nas atividades que permitem conseguir uma vantagem estratégica, nomeadamente por proporcionarem maior valor percebido para - cliente e onde a empresa tenha ou possa vir a ter uma vantagem competitiva distintiva. Os atributos geradores de valor para os clientes no uso do computador pessoal que a Microsoft desenvolveu se assentam no sistema operacional, na interface de fácil utilização e numa gama alargada de aplicativos que aumentam a sua funcionalidade (HAMEL e PRAHALAD, 1995).

Kim e Maugborgne (2005) afirmam que a definição do preço estratégico é fundamental para conseguir um fluxo de caixa adequado, ao permitir estabelecer o preço a um nível que capte uma massa significativa de consumidores. A produção do primeiro Windows XP para a Microsoft custou uma fortuna, porém a produção em massa reduziu o custo de produção para pouco mais do custo de um cd (compact disk). O preço adequado ao consumo de massa foi fundamental para cobrir os custos de desenvolvimento e gerar um fluxo de caixa positivo. 
Bhide (1994) ressalta a visão empreendedora do funcionamento das organizações de sucesso. Uma das formas de implementar esta visão empreendedora é o aproveitamento inovador e rápido das oportunidades do ambiente externo proporcionadas por um novo setor ou por um setor em mudança. Para o autor, Bill Gates transformou a Microsoft numa empresa multibilionária sem um produto revolucionário. Gates aproveitou ser o primeiro a chegar e capitalizou nas oportunidades de um setor em mudança. Segundo Hamel e Prahalad (1995) a Microsoft tornou-se padrão no mercado para o DOS e depois para o Windows, colocando a empresa numa posição vantajosa para o desenvolvimento de aplicativos que também se tornaram padrão universal, como o MSOffice.

O caso da Microsoft exalta mais uma vez a importância do líder e da sua TMT. O foco do negócio continua claro, tornar padrão de utilização naquilo que se dedica á semelhança do que aconteceu com o Windows e Office. O sucesso desta aposta e no software levou a Microsoft a tornar-se alvo de fortes pressões externas. A importância dos recursos humanos ficou evidenciada como recurso chave para a organização. E, finalmente a venda de grandes volumes com custos baixos de produção sustenta financeiramente a estratégia da empresa.

ANÁLI SE DOS CASOS: Des(en)cobrindo os pilares da estratégia Neste estudo propomo-nos relaconar algumas dimensões determinantes do desempenho, que complementam ou orientam a identificação dos recursos a serem desenvolvidos na conquista de melhor desempenho. Deste modo, os pilares estratégicos são apresentados segundo a abordagem da RBV. 
A análise dos cinco casos nas referências selecionadas permitiram-nos identificar quatro dimensões determinantes para o desempenho de uma estratégia de sucesso. Designamos estas dimensões de pilares da estratégia, são elas: liderança e equipe executiva; foco estratégico; aposta no futuro e sustentação pelos recursos (Figura 1).

FI GURA 1. Framework proposto

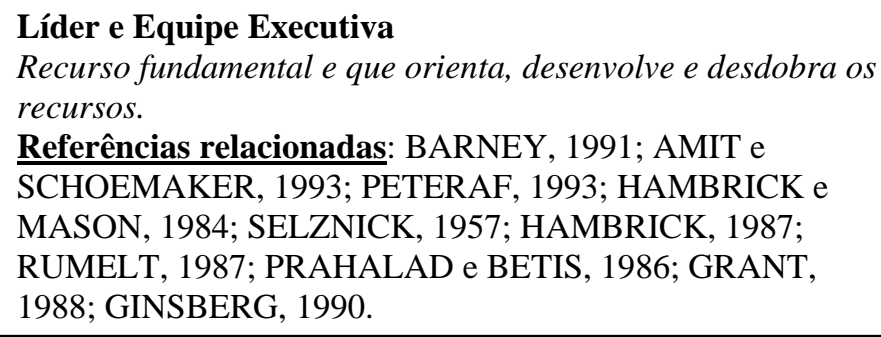

Referências relacionadas: BARNEY, 1991; AMIT e SCHOEMAKER, 1993; PETERAF, 1993; HAMBRICK e MASON, 1984; SELZNICK, 1957; HAMBRICK, 1987; RUMELT, 1987; PRAHALAD e BETIS, 1986; GRANT, 1988; GINSBERG, 1990.

\section{Foco Estratégico}

Futuro desejado representado pela intenção estratégica, visão empreendedora ou teoria do negócio. Orienta o rumo da organização, sendo assim, fundamental para a escolha dos recursos fundamentais para alcançá-lo.

Referências relacionadas: HAMEL e PRAHALAD, 1989; DRUCKER, 1994; COLLINS e PORRAS, 1998.

\section{Aposta \\ Manter-se competitivo ou crescer como corporação exige assumir riscos de mudança, sobretudo desenvolver e utilizar recursos que levam a novos posicionamentos, à inovação. \\ Referências relacionadas: WERNERFELT, 1984; \\ LIEBERMAN, 1987; LIEBERMAN e MONTGOMERY, 1988a, 1988b; RUMELT, 1987; TEECE e PISANO, 1994.}

\section{Sustentação pelos Recursos}

Necessidade de recursos humanos e financeiros para dar suporte ao desenvolvimento dos demais recursos.

Referências relacionadas: PENROSE, 1959; MAHONEY, 1992, 1995, 2001; DOSI e TEECE, 1993; FOSS, 1996.

Nas empresas analisadas estes pilares sustentam o sucesso. Estas dimensões, na perspectiva da RBV, orientam a identificação, desenvolvimento e desdobramento de recursos que possam atender aos critérios de valor, raridade, imitabilidade imperfeita e não são facilmente 
substituíveis, o que os qualifica como recursos estratégicos. Ainda segundo a categorização de recursos segundo Barney (1991), os pilares enquadramse como recursos intangíveis e, sobretudo de capital humano.

O framework apresentado na Figura 1 representa cada uma das dimensões individualmente, assim como a ligação entre elas. Exemplos de ações e aspectos relacionados a estes pilares, para cada caso, são apresentados no Quadro 3, e servem de suporte à descrição dos pilares identificados.

\section{- Pilar 1: O papel do líder e da sua equipe executiva}

Não é o objetivo aqui discutir o conceito de liderança mas reconhecer que o rumo das organizações é estabelecido por um, ou poucos, indivíduos identificáveis. O papel do líder é complementado pelo empenho dos colaboradores da organização. Aliás, este empenho é conseguido pela equipe executiva na liderança. A influência fundamental do líder manifestase não apenas na formulação da estratégia, mas em toda a visão e direção que a empresa deve tomar, quer dizer, na intenção estratégica (HAMEL e PRAHALAD, 1995). O líder e a equipe executiva sempre foram considerados recursos importantes na abordagem da RBV, na medida em que influenciam a exploração e a prospecção de recursos (BARNEY, 1991; AMIT e SCHOEMAKER, 1993; PETERAF, 1993). Toda a equipe de executivos (TMT) influencia significativamente na tomada de decisão estratégica, pela formação, conhecimento, habilidades e estilo cognitivo do TMT, formas e redes de relacionamentos estabelecidas internamente (HAMBRICK e MASON, 1984) e pelo seu talento gerencial (SELZNICK, 1957; HAMBRICK, 1987). Uma equipe com um nível mais alto de educação formal influencia a 
complexidade administrativa e a utilização de ferramentas de gestão mais sofisticadas (PAPADAKIS e BARWISE, 2002).

O líder e seu TMT são recursos valiosos, visto que permitem à firma conceber e implementar estratégias para explorar oportunidades e neutralizar ameaças (BARNEY, 1991). Bons líderes são recursos raros e de difícil substituição. Rumelt (1984), por exemplo, reconhece a capacidade distintiva do líder empreendedor de proteger seu negócio pela inovação. A importância do líder é reconhecida na pesquisa sobre empreendedorismo considerando a organização e o empreendedor dependentes do caminho (path dependent). Isto leva a considerar a complexidade social e a ambigüidade causal, pois é difícil compreender o processo e a forma como as decisões sobre recursos são tomadas, e as inter-relações com o TMT (GARTNER, 1988). As capacidades sócio-cognitivas da TMT são vistas como recursos que induzem a heterogeneidade na indústria (PRAHALAD e BETIS, 1986), ou, como suas decisões são discricionárias sobre o desenvolvimento e desdobramento dos recursos que contribuem para rendas sustentáveis (AMIT e SCHOEMAKER, 1993). O líder e a TMT são recursos inimitáveis, pois a tomada de decisão é dependente da competência individual do líder e da forma de implementação da decisão tomada (AMIT e SCHOEMAKER, 1993). Bons líderes isolam suas organizações da imitação por atuar de forma excepcional para manter e obter a lealdade de clientes, criar inovações e encontrar oportunidades (RUMELT, 1984).

Nos casos estudados, o líder e o TMT emergiram como um recurso determinante para o sucesso. O líder e o TMT são raros e não substituíveis. São difíceis de imitar e seu desempenho extraordinário em determinada empresa não são garantia que terão desempenho equivalente em outra. 


\section{- Pilar 2: Para implementar algo é preciso ter Foco}

O foco estratégico partilha várias características com a intenção estratégica, tal como proposta por Hamel e Prahalad (1989). O foco estratégico deve combinar dois elementos: a visão corporativa e o desejo para que se torne realidade. Assim, o foco estratégico, representado como intenção estratégica (HAMEL e PRAHALAD, 1989), teoria do negócio (DRUCKER, 1994) ou visão corporativa (COLLINS e PORRAS, 1998) é uma das conseqüências das ações do valioso, raro, inimitável e não substituível líder e por essa razão assume estas mesmas características. Afinal, é o líder quem provê a orientação para a organização. O foco estratégico está também fortemente relacionado com a visão de longo prazo do empreendedor e orienta a visão do empreendedor na persecução de oportunidades e modelos ou conceitos de negócio a desenvolver para um melhor ajustamento às variações no ambiente externo e interno à organização (MALHEIROS, 2003).

A existência e a continuada atualização do foco estratégico requerem atenção especial na avaliação da análise interna da organização. Por exemplo, o foco estratégico dirige as estratégias de investimento face ao status quo interno e as oportunidades emergentes, Também estabelece prioridades na alocação dos recursos escassos entre as várias unidades de negócio, permite construir critérios objetivos para a reestruturação das carteiras de negócios de empresas diversificadas, facilita a focalização nas fases da cadeia de valor onde a empresa pretende estabelecer a sua base de diferenciação, entre outros. 
QUADRO 3. Pilares da Estratégia das organizações estudadas

\begin{tabular}{|c|c|c|c|c|c|}
\hline $\begin{array}{c}\text { Organizaç } \\
\text { ões }\end{array}$ & HONDA (50-70) & SWATCH (80 e 90) & GE ( 80 e 90) & $\begin{array}{c}\text { SOUTHWEST (70- } \\
90)\end{array}$ & MI CROSOFT (70-90) \\
\hline Situação & $\begin{array}{l}\text { Entrada e liderança } \\
\text { posterior da Honda no } \\
\text { mercado de } \\
\text { motocicletas norte- } \\
\text { americano. }\end{array}$ & $\begin{array}{l}\text { Formação e liderança da } \\
\text { Swatch no mercado de } \\
\text { relógios mundial de baixo } \\
\text { preço com liderança de } \\
\text { empresas japonesas. }\end{array}$ & $\begin{array}{l}\text { Retoma da } \\
\text { competitividade e } \\
\text { evolução do trabalho } \\
\text { dos CEO anteriores } \\
\text { para } \\
\text { dimensionamento do } \\
\text { nível de } \\
\text { descentralização } \\
\text { adequado. }\end{array}$ & $\begin{array}{l}\text { Formação e } \\
\text { liderança na } \\
\text { indústria de aviação } \\
\text { em crise e saturada } \\
\text { dos EUA. }\end{array}$ & $\begin{array}{l}\text { Aproveitamento de } \\
\text { oportunidades e de } \\
\text { flexibilidade para } \\
\text { manter-se na liderança } \\
\text { pela competência de } \\
\text { seus recursos humanos. }\end{array}$ \\
\hline Líder & $\begin{array}{l}\text { Soichiro Honda } \\
\text { (empreendedor) }\end{array}$ & $\begin{array}{l}\text { Nicolas Hayek } \\
\text { (empreendedor) }\end{array}$ & $\begin{array}{l}\text { Jack Welch } \\
\text { (executivo) }\end{array}$ & $\begin{array}{l}\text { Herb Kelleher } \\
\text { (empreendedor) }\end{array}$ & $\begin{array}{l}\text { Bill Gates } \\
\text { (empreendedor) }\end{array}$ \\
\hline $\begin{array}{c}\text { Equipe } \\
\text { executiva }\end{array}$ & $\begin{array}{l}\text { Takeo Fuj isawa (sócio } \\
\text { e executivo). } \\
\text { Inicialmente mais } 3 \\
\text { diretores e crescendo } \\
\text { pelas necessidades. }\end{array}$ & $\begin{array}{l}\text { Formada ao longo do } \\
\text { tempo, em função das } \\
\text { necessidades e desafios. } \\
\text { Preocupou-se com a } \\
\text { sucessão - Haeyek J r. } 21 \\
\text { membros do comitê } \\
\text { executivo no final do } \\
\text { período. }\end{array}$ & $\begin{array}{l}\text { Formada ao longo do } \\
\text { tempoem função das } \\
\text { com-petências } \\
\text { pessoais, mérito e } \\
\text { desafios e citada } \\
\text { explicita-mente em } \\
\text { seus livros. }\end{array}$ & $\begin{array}{l}\text { Vice-presidente } \\
\text { James (J im) Parker } \\
\text { e como Diretora } \\
\text { Geral e de } \\
\text { Operações Colleen } \\
\text { Barret. } \\
\text { Mudando e } \\
\text { progredindo com a } \\
\text { necessidade. }\end{array}$ & $\begin{array}{l}\text { Paul Allen (sócio) } \\
\text { Steve Balmer (braço } \\
\text { direito) }\end{array}$ \\
\hline $\begin{array}{c}\text { Foco } \\
\text { estratégic } \\
0\end{array}$ & $\begin{array}{l}\text { "Sonho grandioso" de } \\
\text { perseguição constante } \\
\text { por tecnologia. }\end{array}$ & $\begin{array}{l}\text { "Indústria suíça não pode } \\
\text { morrer". }\end{array}$ & $\begin{array}{l}\text { "Vamos tocar somente } \\
\text { negócios que sejam o } \\
\text { núme-ro um ou o } \\
\text { número dois nos seus } \\
\text { mercados globais". }\end{array}$ & $\begin{array}{l}\text { "Velocidade do avião } \\
\text { a preço de carro" }\end{array}$ & $\begin{array}{l}\text { "Um computador em } \\
\text { cada mesa e em cada } \\
\text { lar, todos rodando } \\
\text { software Microsoft em } \\
\text { cada computador" }\end{array}$ \\
\hline $\begin{array}{l}\text { Aposta no } \\
\text { futuro }\end{array}$ & $\begin{array}{l}\text { Entrada no mercado } \\
\text { americano de } \\
\text { motocicletas } \\
\text { com comportamento } \\
\text { de consumo distinto e } \\
\text { com concorrentes } \\
\text { fortes na década de } \\
50 \text { e, posteriormente } \\
\text { no mercado saturado }\end{array}$ & $\begin{array}{l}\text { Utilização dos recursos } \\
\text { no foco da estratégia; . } \\
\text { Desenvolver um relógio } \\
\text { barato com produção } \\
\text { suíça, com tecnologia e } \\
\text { mensagem na contra-mão } \\
\text { da indústria. } \\
\text { Sair do apelo funcional } \\
\text { para o emocional. }\end{array}$ & $\begin{array}{l}\text {.Foco: desfazer-se de } \\
\text { uma série de negócios } \\
\text { em que não poderia } \\
\text { se tornar competitivo } \\
\text { o suficiente. Viabilizar } \\
\text { negócios de } \\
\text { participação } \\
\text { tradicional da GE com } \\
\text { queda de }\end{array}$ & $\begin{array}{l}\text { Adoção de cadeia } \\
\text { de valor } \\
\text { completamente } \\
\text { distinta da usual na } \\
\text { indústria. } \\
\text { Busca por um novo } \\
\text { mercado - usuários } \\
\text { de automóveis e } \\
\text { ônibus. }\end{array}$ & $\begin{array}{l}\text {. Tornar-se padrão no } \\
\text { mercado, sedo o } \\
\text { primeiro ou o mais } \\
\text { rápido a conquistá-lo } \\
\text { em “oportunidades com } \\
\text { externalidades de rede } \\
\text { - caso haja, vantagens, } \\
\text { para a grande maioria } \\
\text { dos consumidores, em }\end{array}$ \\
\hline
\end{tabular}




\begin{tabular}{|c|c|c|c|c|c|}
\hline & $\begin{array}{l}\text { de automóveis na } \\
\text { década de } 70 .\end{array}$ & & $\begin{array}{l}\text { competitividade. } \\
\text { Acabar com a } \\
\text { burocracia. }\end{array}$ & & $\begin{array}{l}\text { dividir um padrão } \\
\text { comum. }\end{array}$ \\
\hline $\begin{array}{l}\text { Sustentab } \\
\text { ili-dade } \\
\text { pelos } \\
\text { recursos }\end{array}$ & $\begin{array}{l}\text {. Competência em } \\
\text { motores; sucesso } \\
\text { anterior e imagem de } \\
\text { marca construída; } \\
\text { capacidade de } \\
\text { inovação; } \\
\text { oportunismo; } \\
\text { eficiência: economia } \\
\text { de escala e } \\
\text { experiência } \\
\text { acumulada; e } \\
\text { sustentabilidade } \\
\text { financeira e de gestão } \\
\text { de recursos. }\end{array}$ & $\begin{array}{l}\text { Recursos financeiros } \\
\text { para o empreendimento; } \\
\text { desenvolvimento de } \\
\text { competências; valorização } \\
\text { dos recursos humanos; } \\
\text { capacidade de inovação } \\
\text { tecnológica; competência } \\
\text { em design; clima } \\
\text { organizacional, imagem } \\
\text { de marca. }\end{array}$ & $\begin{array}{l}\text { Direcionamento dos } \\
\text { recursos financeiros } \\
\text { para o foco da } \\
\text { estratégia; aquisição } \\
\text { de novas } \\
\text { competências; } \\
\text { inovação; participação } \\
\text { e comprometimento } \\
\text { da base da pirâmide. }\end{array}$ & $\begin{array}{l}\text {. Capacidade de } \\
\text { simplificar as } \\
\text { atividades; emprego } \\
\text { e valorização das } \\
\text { pessoas; padrão de } \\
\text { distribuição dos } \\
\text { recursos que } \\
\text { possibilita que os } \\
\text { tempos em terra } \\
\text { sejam menores; e } \\
\text { utilização focada dos } \\
\text { recursos. }\end{array}$ & $\begin{array}{l}\text { Qualidade do pessoal e } \\
\text { estilo da gerência; } \\
\text { valorização dos recursos } \\
\text { humanos; utilização } \\
\text { focada dos recursos; } \\
\text { inovação e velocidade. }\end{array}$ \\
\hline
\end{tabular}

Fonte: Autores

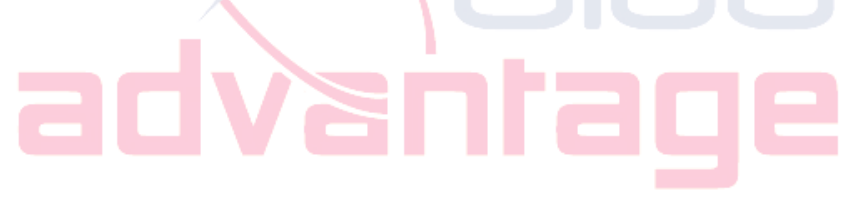




\section{- Pilar 3: Apostando para ganhar}

A aposta está ligada ao risco para uma grande mudança ou, principalmente, para uma grande recompensa. Envolve ameaças e fraquezas procurando mudar sua natureza e não se proteger ou atenuar, respectivamente. No levantamento dos casos de sucesso e de longevidade, verifica-se que existe uma aposta que não ignora os fatores desfavoráveis. Isto não quer dizer que as forças e oportunidades não sejam importantes, mas consideram o momento. Os desfavoráveis são mais impactantes no futuro da organização e, por isto, atenuam o problema fundamental da estratégia, ligado ao que pode e está por acontecer.

A aposta da organização para alcançar seu foco estratégico em qualquer setor é importante. Pode-se chamar isto de reinventar o negócio, como Hamel e Prahalad (1995), ou criar novas demandas nos setores, como ensinam Kim e Maugborgne (2005). O que se quer dizer é que a atratividade dos setores vai variar no longo prazo e raramente não haverá alguma organização com desempenho destacado. A aposta, apresentada aqui como fator determinante para o desenvolvimento de recursos estratégicos, extrapola a visão da análise SWOT quando em relação às empresas explorarem suas forças para alavancar as oportunidades. Leva as empresas a não se limitarem a neutralizar ameaças e prevenir as fraquezas, antes trabalham para tornar suas fraquezas em forças e ameaças em oportunidades.

Utilizando como exemplo o conceito clássico da RBV de "first mover advantage" (WERNERFELT, 1984), todas as companhias que em certo momento histórico aproveitaram-se desta vantagem, por tornarem-se padrão do mercado (a Microsoft, por exemplo) devido a reputação positiva com certa competência ou por oferecer melhor preço em função das vantagens de custo (Southwest, por 
exemplo), tiveram que assumir os riscos de serem a primeira. Algo extraordinário deve acontecer, uma novidade deve ser oferecida (RUMELT, 1987).

\section{- Pilar 4: Sustentação pelos Recursos}

O trabalho de Penrose (1959) é considerado como a base da abordagem teórica da RBV (WERNERFELT, 1984; RAMOS-RODRIGUEZ and RUIZ-NAVARRO, 2004). Penrose (1959) argumenta que o crescimento das firmas depende do uso efetivo de recursos heterogêneos e fundamentalmente de seus recursos humanos.

Wernerfelt (1984) citou exemplos de alguns recursos como marca, tecnologia própria, pessoal qualificado, contratos comerciais, maquinaria, procedimentos eficientes, capital, etc. Parece razoável propor que todos estes recursos estão relacionados com duas categorias de recursos primários, são estes os recursos financeiros e os recursos humanos. Como recurso financeiro, pode-se incluir não só o capital, mas também a habilidade de gerenciá-lo. De modo idêntico para os recursos humanos, ou seja, para qualquer recurso de valor existe uma necessidade específica de recursos humanos. A maior pressão para crescimento rápido e de diversificação da firma, por exemplo, recai sobre os recursos financeiros e humanos. (BARNEY, 2001).

A importância dos recursos é particularmente notória nas pequenas e médias empresas bem como nas novas empresas empreendedoras. As novas empresas têm na sua maioria, estatisticamente, longevidade inferior a um ano (STINCHCOMBE, 1965). Uma das maiores lacunas nestas empresas é exatamente a insuficiência de recursos financeiros e humanos para se estabelecerem no mercado. 


\section{NOTAS FI NAIS}

Neste artigo foram apresentadas quatro dimensões determinantes do desempenho organizacional, chamados aqui de pilares, para auxiliar na avaliação e desenvolvimento de recursos estratégicos que orientem a busca por vantagem competitiva.

O primeiro pilar é o líder e a sua equipe executiva que, apesar de serem recursos fundamentais e básicos para o desenvolvimento da estratégia futura e, assim para a tomada de decisão para aproveitar, desenvolver ou desdobrar recursos organizacionais, não são normalmente considerados na formulação de estratégias.

O segundo é o foco estratégico, que encaminha as atuações da empresa. É bastante utilizado sobre a firma de visão e missão organizacional, entretanto, é formulado ou validado pelo líder e pela equipe executiva, orientando significativamente a escolha de rumos e da utilização dos recursos organizacionais.

Para uma recompensa adequada é preciso um terceiro pilar, uma aposta que possibilite um salto no desempenho da organização. Neste caso, relacionado à escolha do desenvolvimento e desdobramento de recursos. E, para que a estratégia seja de fato implementada há o suporte de recursos humanos e financeiros adequados em quantidade e qualidade. Estes pilares foram identificados a partir da análise de estudos de caso, assim como, de exemplos e conceitos de referências clássicas da literatura de estratégia e visam orientar a análise interna das organizações.

Apesar de a RBV ter vindo contribuir sobremaneira com o estudo acadêmico da estratégia (RAMOS-RODRIGUEZ e RUIZ-NAVARRO, 2004), sua utilização prática padece ainda de várias limitações que resultam em críticas: sua 
natureza tautológica (PRIEM \& BUTLER, 2001), dificuldade de identificar os recursos VRIN, complexidade envolvida na avaliação a priori do valor dos recursos, e definição imprecisa de quais os recursos seriam capazes de gerar uma vantagem competitiva (PRIEM e BUTLER, 2001). Nesse contexto, esta pesquisa visou contribuir para a busca e desenvolvimento de recursos estratégicos a partir da avaliação dos pilares propostos. Sugere-se ainda para trabalhos futuros o desenvolvimento ou a adaptação de ferramentas para análise interna das organizações com base nos pilares aqui propostos.

\section{REFERÊNCIAS}

AMIT, R. \& SCHOEMAKER, P. (1993) Strategic assets and organizational rents. Strategic Management J ournal, 14, p. 22 - 46.

BARNEY, J. B. (1986) Strategy factor markets: Expectations, luck and business strategy.

Management Science, 42, p. 1231 - 1241.

BARNEY, J. B. (1991) Firm resources and competitive advantage. Journal of Management, 17, p. 99 - 120.

BHIDE, A. (1994) How entrepreneurs craft strategies that work. Harvard Business Review. P. 150 - 161. Mar/Apr.

BIGNETTI, L. P. \& PAIVA, E. L. (2001) Estudo das citações de autores de estratégia na produção acadêmica brasileira. In: $25^{\circ}$ Encontro Nacional da Associação Nacional de Pós-graduação em Administração - Campinas: Anais. ANPAD.

COLLINS, J. C. \& PORRAS, J. I. (1998) Feitas para durar: Práticas bem-sucedidas de empresas visionárias. Rio de Janeiro: Editora Rocco.

DIERICKX, I. \& COOL, K. (1989) Asset stock accumulation and sustainability of competitive advantage. Management Science, 35 (12), p. 1504 - 1511.

DOSI, G. \& TEECE, D. (1993) Organizational competences and the boundaries of the firm, CCC Working paper. N 93-11, University of California at Berkley, CRM.

DRUCKER, P. (1994) The theory of business. Harvard Business Review. Sept/Oct. FOSS, N. J. (1997) Resources and strategy: problems, open issues, and ways ahead. In Foss, N. J. (Ed) Resources, Firms, and Strategies: A Reader in the ResourceBased Perspective. p. 345-265. Oxford: Oxford University Press.

GALBREATH, J. (2004) Determinants of Firm Success: A Resource-Based Analysis.

Doctoral Thesis. Graduate School of Business. Curtin Business School. Dec.. 
GARTNER, W. B. (1988) Who is an entrepreneur?' Is the wrong question. American J ournal of Small Business, 12, 4 (Spring), p. 11-32.

GHEMAWAT, P. (2000) A estratégia e o cenário dos negócios. Porto Alegre: Editora Bookman.

GRANT, R. (1988) On "dominant logic" and the link between diversity and performance.

Strategic Management J ournal, 9, p. 41 - 58.

HAMBRICK, D. (1987) Top management teams: Key to strategic success. California Management Review, 30, p. 88 - 108.

HAMBRICK, D. \& MASON, P. (1984) A. Upper echelons: The organization as a reflection of its top managers. Academy of Management Review, 9, p. 193 - 206.

HAMEL, G \& PRAHALAD, C. K. (1989) Strategic intent. Harvard Business Review, May /J une, pp 63-76.

HAMEL, G. \& PRAHALAD, C. K. (1995) Competindo pelo futuro. Rio de J aneiro: Editora Campus.

KAY, J., MCKIERNAN, P. \& FAULKNER, D. (2003) The history of strategy and some thoughts about the future. In: FAULKNER, D.; CAMPBELL, A. (Org.) Oxford Handbook of Strategy. v. 1 - A Strategy Overview and Competitive Strategy. Oxford: Oxford University Press.

KIM, W. C. \& MAUGBORGNE, R. (2000) Knowing a winning business idea when you see one. Harvard Business Review, Boston, p. 129 - 137, sept.-oct..

KIM, W. C. \& MAUGBorgne, R. (2005) A estratégia do oceano azul: Como criar novos mercados e tornar a concorrência irrelevante. Rio de J aneiro: Elsevier.

KIM, W. C. \& MAUGBORGNE, R. (1999) Creating a new marketing space. Harvard Business Review, Boston, p. 129 - 137, jan.- feb.

KLEI NER, A. (2003) GE's next workout. Strategy+business, 33, p. Booz Allen Hamilton Inc.

LIEBERMAN, M. \& MONTGOMERY, D. (1988a) First-mover advantages. Strategic Management J ournal, 8 (5), p. $441-452$

LIEBERMAN, M. \& MONTGOMERY, D. (1988b) First-mover (dis)advantages: Retrospective and link with the reource-based view. Strategic Management J ournal, 19 (12), p. 1111- 1125.

LIEBERMAN, M. B. (1987) The learning curve, diffusion and competitive strategy. Strategic Management Journal, 8 (5), p. 441 - 452.

MALHEIROS, R. (2003) Viagem ao mundo do Empreendedorismo. IEA: Florianópolis. MICHALISIN, M. D., SMITH, R. D. \& KLINE, D. M. (1997) In search of strategic assets. International J ournal of Organizational Analysis, 5(4), p. 360-387.

MINTZBERG, H., AHLSTRAND, B. \& LAMPEL, J. (2000) Safári da estratégia: Um roteiro pela selva do planejamento. Porto Alegre: Editora Bookman. 
MINTZBERG, H., PASCALE R. T., GOOLD, M. \& RUMELT, R. (1996) The "Honda Effect" revisited. California Management Review, 38 (4), pp. 78 - 79.

MOON, Y. (2004) The birth of Swatch. Harvard Business School, Boston, p. 1 - 15.

PAPADAKIS, V. \& BARWISE, P. (2002) How much do CEO's and Top Managers matters in strategic decision making. British J ournal of Management, 13, p. 83-95.

PASCALE, R. (1996) The Honda Effect. California Management Review, 38 (4). p. 80 91.

PASCALE, R. (1984) Perspectives on strategy: The real story behind Honda's success. California Management Review, v. 26, n.3.

PENROSE, E. (1959) The theory of the growth of the firm. ( $3^{\text {rd }}$ ed.) Oxford, UK: Oxford University Press.

PETERAF, M. A. (1993) The cornerstones of competitive advantage: A resource-based view. Strategic Management J ournal, 14, p. 179 - 191.

PORTER, M. E. (1980) Competitive strategy: Techniques for analyzing industries. New York: Free Press.

PORTER, M. E. (1985) Competitive advantage: Creating and sustaining superior performance. New York: Free Press.

PORTER, M. (1986) Estratégia competitiva: Técnicas para análise de indústria e da concorrência. Rio de Janeiro, Editora Campus.

PORTER, M. (1989) Vantagem competitiva: Criando e sustentando um desempenho superior. Rio de Janeiro: Editora Campus.

PORTER, M. (1996) What's strategy? Harvard Business Review, Boston, p. 61 - 78, nov.-dec.

PRAHALAD, C. K. \& BETTYS, R. (1986) The dominant logic: A new linkage between diversity and performance. Strategic Management J ournal, 7, p. 485 - 501.

PRIEM, R. \& BUTLER, J. (2001) Tautology in the Resource-Based View and the implications of externally determined resource value: Further comments. Academy of Management Review, 26 (1), p. 57 - 66.

QUINN, J. B. \& HILMER, F. G. (2004) Strategic Outsourcing. Sloan Management Review. Summer.

RAMOS-RODRIGUEZ A. \& RUIZ-NAVARRO, J. (2004) Changes in the intellectual structure of strategic management research: A bibliometric study of the Strategic Management Journal, 1980- 2000. Strategic Management J ournal, 25, p. 981 - 1004.

RUMELT, R. (1984) Towards a strategic theory of the firm. In R. B. Lamb (ed.) Competitive Strategic Management. Upper Sadler River, NJ : Prentice Hall.

RUMELT, R. (1987) Theory, Strategy and Entrepreneurship. In D. Teece (ed.), The competitive challenge: Strategies for industrial innovation and renewal, Chapter 7, p. 137 - 158, Cambridge, MA: Ballinger. 
SELZNICK, P. (1957) Leadership in administration: A sociological interpretation.

Evanston, IL: Row Peterson.

STAUFER, D. (1997) What you can learn about managing from Microsoft. Harvard Management Update, p. 3- 5.

STINCHCOMBE, A. (1965) Social structure and organizations. In Handbook of

Organizations, ed. J. G. March. p. 153 - 193. Chicago: Rand McNally \& Company.

TICHY, N. \& CHARAN, R. (1989) Speed, Simplicity, Self-Confidence: An interview with Jack Welch. Harvard Business Review, sept. - oct..

ULRICH, D.; KERR, S. \& ASHKENAS, R. (2002) The GE work-out: How to implement

GE's revolutionary method for busting bureaucracy and attacking organizational problems - fast!. New York: McGraw-Hill.

VASCONCELLOS, F. \& CYRINO, A. (2000) Vantagem Competitiva: Os modelos teóricos atuais e a convergência entre estratégia e teoria organizacional. RAE - Revista de Administração de Empresas, São Paulo, v. 40, n. 4, p. 20 - 37, out.-dez..

VERGARA, S. C. (1997) Projetos e relatórios de pesquisa em administração. São Paulo: Editora Atlas.

WERNERFELT, B. (1984) A Resource-Based View of the firm.. Strategic Management Journal, 5, p. 171 - 180.

YIN, R. K. (2005) Estudo de caso: Planejamento e métodos. Porto Alegre: Editora Bookman. 